Asia Pacific Journal of Management DOI 10.1007/s10490-015-9426-z

Hong T. M. Bui \& Yehuda Baruch \& Vinh S. Chau \&Hong-Wei He

\title{
Team learning: the missing construct from a cross-cultural examination of higher education
}

\begin{abstract}
Team learning should be an important construct in organizational management research because team learning can enhance organizational learning and overall performance. However, there is limited understanding of how team learning works in different cultural contexts. Using an international comparative research approach, we developed a framework of antecedents and outcomes in the higher education context and tested it with samples from the UK and Vietnam. The results show that a common framework is applicable in the two different contexts, subject to slight modifications. However, this study does not find that team learning (measured via the proxy of 'attitude towards team learning') exhibits any statistically significant relationship as a predictor of the proposed outcomes. Other findings from this study on educational contexts are important not only to scholars in this field, but also for practicing managers, particularly those who study and operate in the extensive global market.
\end{abstract}

\section{Key Words:}

Team learning; organizational culture; people management; leadership; Vietnam; United Kingdom 


\section{Introduction}

Individual learning and collective learning demonstrate the potential for and significance of double-loop transformational changes in organizations (Bresman \& Zellmer-Bruhn, 2013; Kostopoulos \& Bozionelos, 2011; Kostopoulos, Spanos, \& Prastacos, 2013; Seo, 2003). Over the past decades, team learning has become the subject of considerable empirical and theoretical attention in the extant literature. Research and theorizing in this area have highlighted the importance of team learning in improving performance, generating knowledge, and sustaining competitive advantage (Ely, Padavic, \& Thomas, 2012; Hirst, Van Knippenberg, \& Zhou, 2009; Li, Chun, Ashkanasy, \& Ahlstrom, 2012). In a recent meta-analysis, Hülsheger, Anderson and Salgado (2009) show evidence of the strong link between team process variables and individual and team innovation.

Team learning - and for this study we use specifically 'attitude towards team learning' as its close proxy - is an important construct in executing organizational research as it is understood to enhance organizational learning and performance (Edmondson, 2002; Kostopoulos et al., 2013; Nonaka \& Takeuchi, 1995) and employee creativity (Hirst et al., 2009). A learning team can continuously foster other learning teams by inculcating the knowledge and skills of team learning more widely (Senge, 2006): yet there is no consensus on its definition. One dominant definition of team learning is "the process of aligning and developing the capacity of a team to create the results its members truly desire" (Senge, 2006, p. 236) which signifies it as a fundamental process within organizations. Elsewhere, team learning is defined as "a change in the group's repertoire of potential behavior" (Wilson, Goodman \& Cronin, 2007, p. 1043). These definitions each focus on different components - process and behaviors. Combining the two, and building on Gibson and Vermeulen (2003) who, 
within in the context of team learning behavior, see it as "a cycle of experimentation, reflective communication, and codification" (p.202), we employ the following definition for our study: team learning is the process by which combined efforts and involvement of team members improve their ability to perform, leading to a change in their actions and outcomes.

There are two outstanding observations in the literature that are of particular relevance to this study. On the one hand, while most scholarly attention has focused on the study of team learning in business sectors, more work is needed in the public sector, particularly in higher education. On the other hand, while team learning is an established research area in the context of developed countries, it remains underdeveloped in the context of developing countries. In particular, comparative research on team learning across cultures is rare. We consider these two points as follows.

The first point is the importance of people management for transformation and innovation within the higher education sector. The dynamic competition in the higher education sector has moved from domestic to global labor markets (Baruch, 2013). Some critics view universities as 'centers of non-learning', which fail to transform knowledge from academics to students and outsiders (Kinchin, Lygo-Baker, \& Hay, 2008); such a failure could be prevented if academics collaborate as a community. The process of learning and knowledge creation has moved towards newer, more flexible forms of operation involving teams, highlighting the special importance of learning and working within teams to achieve higher levels of knowledge and skills (Bacon \& Blyton, 2003; Prichard \& Ashleigh, 2012) to cope with constant changes at work. This trend poses challenges for human resource (HR) managers within the higher education sector. 
Current research on team learning in higher education has mainly focussed on students (Chen, Donahue, \& Klimoski, 2004; Jassawalla, Sashittal, \& Malshe, 2009; Tashchian, Forrester, \& Kalamas, 2014) and top management (Quian, Cao, \& Takeuchi, 2013; Raes, Bruch, \& De Jong, 2013; Woodfield \& Kennie, 2008). Team learning among employees in higher education is an under-studied area of inquiry (Nissala, 2005), particularly in less developed countries. Team learning challenges leaders and managers in how to enable talented individuals to work together to achieve a collective vision in the context of a highly competitive and increasingly globalized environment (Baruch \& Hall, 2004; Milia \& Birdi, 2010). In addition, team learning is widely recognized as making a significant contribution to organizational changes and successes (Edmondson, Bohmer, \& Pisano, 2001; Senge, 2006), and individual creativity (Hirst et al., 2009).

The second point is the paradoxical difference between the contexts of developed and developing countries in which team learning is typically been studied. Team learning has been investigated for more than three decades in the developed countries (De Geus, 1988; Senge, 1990) but remains merely an emerging topic in the context of developing countries. One such study is that of Tjosvold, Yu and Hui (2004) who highlight aspects of team learning in China that are not covered in Western literature, particularly in relation to 'blame'. Another exception is the study by Ooi, Cheah, Lin and Teh (2012), in which they employ Malaysian middle managers to show a strong link between team learning and knowledge sharing. Research on team learning in the Asian context is fragmented. One clear contextual difference is that developed countries, such as the US and those in Europe, where team learning has been well-developed, tend to have individualist cultures, while 
developing countries tend to have collectivist cultures (Hofstede, 2001; House, Hanges, Javidan, Dorfman, \& Gupta, 2004; Wang, Tjosvold, Chen, \& Luo, 2014).

Why collective learning is well-nurtured in individualist cultures, but less so in collectivist cultures, is an interesting direction for future research. We provide a new angle for understanding possible differences within the scope of the present study. Moving from 'gap-spotting' to 'path-setting' (Alvesson \& Sandberg, 2013) and responding to the call of the Asia Pacific Journal of Management (Ahlstrom, 2012), we develop and test a model of team learning with a set of antecedents and outcomes. We test the antecedents' impact on the outcomes through the mediation of team learning. To test for its validity, we collected empirical data from two well-established universities, one in Vietnam and one in the United Kingdom (UK). The reason for this choice is to compare different countries with varied characteristics, following calls for study of people management in a wider global context (Collings, Morley, \& Gunnigle, 2008; Yang, Sun, Lin, \& Peng, 2011).

The UK is a developed country and, in terms of cultural dimensions, is very high in individualism and masculinity and low in power distance and uncertainty avoidance (Hofstede, 1984, 2001). From a market flow perspective, the UK is a globally significant exporter of higher education - as a commodity, higher education services such as university degrees and specific/specialist training, are in high demand from overseas customers. In contrast, Vietnam, a developing country, has a collectivist culture, and its people appreciate harmonious relationships (Smith \& Pham, 1996; Thêm, 1999; Vượng, 2001; Vuong, Thanh, Ben, Dzung, \& Anh, 1999). From a market flow perspective, Vietnam is a large importer of higher education - its citizens typically purchasing higher education services supplied by other, mostly 
Western, countries. In both countries, universities are in the public sector, and an issue of consideration for human resource management (Pichault, 2007).

The different cultural contexts of team learning theory and their influences on individuals' development may be better understood through developing and testing them within a conceptual model of international comparative research design. It is also of benefit to understand how individuals and organizations can support team learning across cultures, particularly during internationalization and globalization processes (Tsai, Baugh, Fang, \& Lin, 2014). As crossing West-East boundaries has become more frequent and easier than ever before, this study offers a new perspective on team learning at work and as a tool for organizational use within a possible integrated process. We propose the following research framework (Figure 1), based on gaps identified in the team learning literature within the context of higher education.

Insert Figure 1 about here

\section{Hypothesis Development}

\section{Antecedents of Team Learning and Knowledge Sharing}

Team learning is deemed "a concerted effort" in improving participation in innovation processes (Molnar \& Mulvihill, 2003, p. 172). Team members learn together and manifest a level of collective intelligence that is greater than the sum of the intelligence of the individual members (Senge, 2006). We employ a similar approach of multilevel and cross-level relationships to adaptive performance investigated by Han and Williams (2008) and Kostopoulos et al. (2013). The individual level consists of motivation and team commitment. The organizational level includes developmental leadership as well as training and development. This is not the only study that 
develops a framework for team learning. Akgun, Lynn, Keskin and Dogan (2013) develop antecedents and outcomes of team learning in IT implementation projects; similarly, Bresman and Zellmer-Bruhn (2013) structure team learning in self-managed pharmaceutical research and development teams. Alongside those studies, we suggest a more comprehensive understanding of team learning components by offering a different perspective on team learning that is more relevant in the higher education sector in particular and in the public sector in general. This is called for because the components of team learning vary significantly, depending on different sectors and possibly context (Akgun et al., 2013; Bresman \& Zellmer-Bruhn 2013), and the type of competition within the team (He, Baruch, \& Lin, 2014).

The merits of knowledge sharing are similar and well documented in the extant literature. It provides a link between the level of individual employees where the knowledge resides with other levels of the organization where competitive advantage is created and sustained, and and this has been extensively researched, particularly in how knowledge sharing can be facilitated by the use of technology (for example, see Hendriks, 1999). Other industries of extensive research in knowledge sharing include hospitality (Srivastava, Bartol \& Locke, 2006), information technology (Faraj \& Sproull, 2000) and engineering (Lee, Gillsepie, Mann \& Wearing, 2010), but there is little documented in education.

\section{Training and development}

Team skills include both generic and specific components (Prichard, Stratford, \& Bizo, 2006), and are considered important for successful learning (Bowen, 1998; Graen, Hui, \& Taylor, 2006). They are not taken for granted; rather, substantial training and development is required. Collaborative learning is enhanced through 
team skills training (Prichard et al., 2006), and team learning entails increased amounts of training and development (Bacon \& Blyton, 2003). Research on team training has focussed primarily on task knowledge but little attention has been paid to the role of social knowledge (Chen et al., 2004; Edmondson, 1999). While the UK places on-job training as a top priority for improved performance (Dalin, 1998), it remains under-researched in the context of Vietnam (Nguyen, Truong, \& Dirk, 2011).

The full extent of knowledge sharing is dependent on how well the systems in place support the process in order to enhance organizational effectiveness Mehrabani and Mohamed (2011) studied this in the context of Malaysia. It is generally assumed that such training schemes are less utilized in developing countries. Thus, a marginal increase in these is likely to have a greater effect on the ability to knowledge-share in Vietnam than in the UK. Hence, we posit the following two hypotheses:

H1a Investment in training and development is positively associated with team learning, and that the relationship is moderated by the culture.

$\mathrm{H} 1 \mathrm{~b}$ Investment in training and development is positively associated with knowledge sharing, and that the relationship is moderated by the culture.

\section{Leadership}

Organizational leaders need to be engaged in a constant learning process (Hogan \& Warrenfeltz, 2003; Li, Chen, Loiu, \& Peng, 2012). Edmondson, Bohmer and Pisano (2004) show that the most successful teams have leaders who proactively manage team learning efforts. Leadership in education is about culture building that allows educators and students to be part of a team that learns collectively (Sackney \& Walker, 2006). This reflects developmental leadership. Effective leaders will inspire 
innovation and creation of knowledge by and for the team members. Leadership should empower and release people's potential, allowing them to flourish and grow, to release their capacity for indefinite improvement (Bell \& Harrison, 1998). The more conscientious leaders are, the more their empowering behavior is contingent on their trust in follower integrity and performance (Hakima, Knippenberg, \& Giessner, 2010). We extend this argument to knowledge sharing, in that developmental leadership is more likely to desire and facilitate knowledge sharing within an organization. Based on the contexts of a developed and a developing country, we propose the following hypotheses:

H2a. Developmental leadership is positively associated with team learning, and that the relationship is moderated by the culture.

H2b. Developmental leadership is positively associated with knowledge sharing, and that the relationship is moderated by the culture.

\section{Team commitment}

Because team learning is a process of aligning and developing the capacity of a team to create the results the whole team truly desires, it requires members' engagement and commitment. Although literature on organizational commitment has been well established (Meyer \& Allen, 1991; Porter, Steers, Mowday, \& Boulian, 1974), team commitment is a less developed research area (Bishop, Scott, \& Burroughs, 2000), particularly in higher education. The few existing studies suggest that teamwork motivate academics to become more committed to the team and the organization (Park, Henkin, \& Egley, 2005; West, 2004): however, Bishop et al. (2000) do indicate that team commitment is highly associated with teamwork. Being committed means that more knowledge is shared to facilitate a continuous cycle of commitment 
in sharing to work together. Team commitment has been widely studied in the UK (Bennett \& Barkensjo, 2005; Strauss, Griffin, \& Rafferty, 2009) whereas it has rarely been explored within the context of Vietnam. Although team commitment has not been specifically studied in a Vietnamese context before there is no reason to doubt its value to be any less. Therefore, we hypothesize that:

H3a. Team commitment is positively associated with team learning, and that the relationship is moderated by the culture.

$\mathrm{H} 3 \mathrm{~b}$. Team commitment is positively associated with knowledge sharing, and that the relationship is moderated by the culture.

\section{Motivation}

It seems that "models of learning are tied to models of motivation" (Hogan \& Warrenfeltz, 2003, p. 77), so motivation is inevitably a key factor in the learning process. Pintrich (2003) links motivational science to learning science. He identified a number of factors that motivate learners, such as competence, adaptive attributions, control beliefs, goals, high level of interest and intrinsic motivation which can be applied to team learning. When team members share common goals and interests they are more likely to learn better in teams (Kostopoulos \& Bozionelos, 2011). We argue that embedded in a collectivist culture, Vietnamese employees are more likely to be intrinsically motivated to contribute to collective learning at work compared with their UK counterparts, who live in an individualist culture. By the same analogy, knowledge sharing also requires a high degree of motivation as it is based on the synergistic collaboration of individuals towards a common goal (Boland \& Tenkasi, 1995); this by nature suggests that this would be more effective if the synergy is sustained (see also Gagne, 2009). Hence, we hypothesize that: 
H4a. Motivation is positively associated with team learning, and that the relationship is moderated by the culture.

H4b. Motivation is positively associated with knowledge sharing, and that the relationship is moderated by the culture.

\section{Antecedents of Self-efficacy}

Self-efficacy is a well-established principle from the field of psychology that recognizes the extent of belief that one has in being able to achieve something (Bandura, 1986). The strength of one's self-efficacy may be the reason for success, but this itself must be fuelled by other positive factors (Srivastava, Bartol, \& Locke, 2006). We propose that these factors are predominantly team learning and knowledge sharing.

Early research by Edmondson (1999) suggests that group security creates a psychological effect on positive learning behavior. While this is not interpreted in her report as team learning per se, the increased learning behavior is a likely proxy for self-efficacy and team learning due to effective group support. Particularly for a knowledge-based environment, it is likely that combined efforts in managing the knowledge acquired, either at the individual level or the group level (i.e., a proxy for knowledge sharing), can positively influence the belief that achieving various tasks is possible. There is no reason to suggest this to be any different in either the UK or Vietnamese contexts. Hence, we hypothesize that:

H5a. Team learning is positively associated with self-efficacy, and that the relationship is moderated by the culture.

H5b. Knowledge sharing is positively associated with self-efficacy, and that the relationship is moderated by the culture. 


\section{Consequences of Self-Efficacy}

The same work by Srivastava et al. (2006) recognized a direct positive link between (team) efficacy and (team) performance level. In a knowledge-based context where individual staff form the basis of performance, the impact on individual learning of self-efficacy is likely to be the same - i.e., also directly positive - and any performance at team level is the mere summation of the individual academics' performances. This is based on the premise that successes raise the level of selfefficacy, and that is likely to form a cycle for future success (see Bandura, 1986), leading to improved research performance, probably due to a higher 'coping behavior' (Bandura, 1977). Bandura's $(1977,1986)$ work reflects self-efficacy as not only how one sees his/her ability to control performance capacity, but also the cognitive processes, emotions and self-regulated behavior involved (Schunk, 1991), which are characteristics of individual learning behavior. These concepts were first developed and utilized in the Western context and only picked up later in Asia. Therefore, any relationship between them is more likely to be stronger in the UK compared with the Vietnamese counterpart. For this reason it is hypothesized that:

H6a. Self-efficacy is positively associated with research performance, and that the relationship is moderated by the culture.

H6b. Self-efficacy is positively associated with individual learning, and that the relationship is moderated by the culture.

\section{Mediating effects}

Based on the above rationale, we combine the above set of hypotheses to manifest the mediating nature of the model, where bringing together the antecedents of Team learning and Knowledge sharing and the impact of Team learning and Knowledge 
sharing on self-efficacy means that Team learning and Knowledge sharing mediate the impact from those antecedents of self-efficacy. Similarly, self-efficacy would mediate the relationships between Team learning and Knowledge sharing and the outcomes of individual learning and performance. Further, following our discussion relating to cultural differences, we propose that the mediating effects may be varied in those two contexts because of the differences we have cited in developing the above hypotheses. Hence, we postulate that:

H7a: Team learning mediates the relationships between its antecedents and selfefficacy.

$\mathrm{H7b}$ : Knowledge sharing mediates the relationships between its antecedents and selfefficacy.

H7c: Self-efficacy mediates the relationships between team learning and research performance, and team learning and individual learning.

$\mathrm{H} 7 \mathrm{~d}$ : Self-efficacy mediates the relationships between knowledge sharing and research performance, and knowledge sharing and individual learning.

\section{Research Methods}

\section{Data and Sample}

We conducted a survey-based study with academic staff of two well-established universities, one in the UK and the other one in Vietnam. Both universities are of similar size in terms of both student and staff numbers. We employed a stratified random sample of staff from different schools in the UK university (similar schools within each university). We received and used 381 fully completed questionnaires from academics (204 in Vietnam and 179 in the UK) after deleting all missing-data questionnaires, which represents an effective response rate of $43 \%$. Table 1 shows the 
main characteristics of the samples in the two countries. The average time that respondents worked for the Vietnam university was 9.1 years, and 7.7 years for the UK university. There were more doctorate holders in the UK sample than in the Vietnamese one (88.3\% compared to $54.4 \%$ ), and more professors in the UK one (17.9\% compared to $2.5 \%)$.

\section{Context of team learning in higher education}

Teams in higher education operate in a slightly different way than is the case in other sectors, and the literature regarding academic teams is under-developed. Academic teams are formed internally in, or externally to, the specific context. An internal team refers to members who all belong to the same organization. For example, a teaching team consists of people who share teaching together. An external team refers to members who forms teams with colleagues from other institutions. Due to high pressures on staff to publish academic research, external teams characterize the UK HE context. Conversely, external teams are not popular in the context of Vietnam HE due to comparatively less pressure on research performance than is the case in its UK counterpart. Thus, team learning in the two specific contexts in our study is different, particularly when we associate it with research performance as an important outcome of this study's framework.

Insert Tables 1 about here

\section{Measures}

The following measures were utilized in this study. (The full list can be seen in the Appendix). 
Development and training: Four items for this measure were adopted from Bui and Baruch (2012). A sample item is 'I receive the training I need to perform my current job effectively'. The Cronbach Alpha coefficient is .86.

Developmental leadership: Six items for this measure were adapted from Marsick and Watkins (2003). A sample item is 'My direct manager usually empowers others to help carry out the organization's vision', with a Cronbach Alpha coefficient of .90 .

Team commitment: Four items for this measure were taken from West (2004). A sample item is 'At work, I let myself be guided by the goals of the team', with a Cronbach Alpha coefficient of .84.

Motivation: Four items for this measure were adopted from Siebold ( 1994). A sample item is 'I work hard and try to do as a good job as possible', with a Cronbach Alpha coefficient of .73.

Attitude towards team learning: Five items of team learning were adopted from Reed (2001). A sample item is 'I am encouraged to solve problems with my colleagues before discussing them with a manager', with a Cronbach Alpha coefficient of .86 .

Knowledge sharing: Four items of micro knowledge sharing were adopted from Bock et al. (2005). A sample item is 'Sharing my knowledge would help this organization achieve its objectives'. This had a high Cronbach Alpha coefficient of .94.

Self-efficacy: A three-item measure was taken from Tierney and Farmer (2002). A sample item is 'I am confident in my ability to do my job', with a Cronbach Alpha coefficient of .76. 
Individual learning: Four items for this measure were adopted from Bui and Baruch (2012). A sample item is 'I like being on a steep learning curve at work'. The Cronbach Alpha coefficient is .86.

Research performance: In order to create an equivalent measure of performance between the two universities, we decided to select research performance because (1) both universities highly appreciated research as a core performance indicator, and (2) research performance was the only and the most objective performance indicator that we could collect in order to minimize research bias. Respondents' research performance was ranked into seven performance scores based on the UK-based system of evaluating research output levels (the Research Assessment Exercise - RAE) before distributing the questionnaires, enabling a crosscheck with the survey responses. The respondents' questionnaire answers and the actual individual research performance were found to be highly correlated $(r=.53$, $\mathrm{p}<.05)$. The high correlation between the self-reported research performance and the actual performance suggests we can assume high reliability and validity for the selfevaluated performance. We use the actual research performance in our analysis to minimize research bias (Podsakoff, Mackenzie, Lee \& Podsakoff, 2003).

The questionnaire was initially drafted in English. We strictly followed the committee approach, back-translation and pre-test procedure (Brislin, 1976; Sperber, Devellis, \& Boehlecke, 1994) when we translated the questionnaire from English into Vietnamese. Seven people assisted in the translation process and 20 people assisted in the pre-test procedure to ensure that the questionnaire was of the highest level of translation and understanding. 


\section{Results}

\section{Data screening}

Multivariate normality was examined through univariate distribution (Tabachnick \& Fidell, 2001). The Kolmogorov-Smirnov test was carried out to investigate the normality of the distribution along with the consideration of skewness, kurtosis values, and histograms. The Kolmogorov-Smirnov test results were all significant (.00). Skewness values ranged from /.03/ to /1.7/ with many negative values. Kurtosis values ranged from /.38/ to /4.7/. Kline (2006) suggests that extreme univariate nonnormality exists when absolute values of skewness indices are greater than 3.0 and absolute values of kurtosis indices are greater than 5.0. The results showed deviation from perfect normality, yet below these thresholds, and thus was not a concern as true normally distributed data are a fiction in the real world (Malgady, 2007).

In addition, the common method variance was examined by Harman's onefactor test (Podsakoff et al., 2003, 2012). The results indicate the presence of 32 factors whose eigenvalues start from $.40 \%$. The cumulative variance explained by the first seven factors accounted for $68.45 \%$ of the variance, while the first factor accounted for $31.56 \%$ of the variance. These results show the data are free from significant common method bias effects (Podsakoff et al., 2003).

Tables 2, 3 and 4 respectively present descriptive statistics, correlations and Cronbach alpha reliability coefficients of the aggregate sample as well as the subsamples of Vietnam and the UK. The hypotheses were tested using structural equation modeling (SEM) following the guidelines of Byrne (2012). The mediation effects follow the procedure advanced by Baron and Kenny (1986). 


\section{Structural Equation Model}

We used Mplus 7 software (following Muthén \& Muthén, 2012) to analyze the fitness of the SEM of our conceptual model with two separate samples from the UK and Vietnam. The overall relationships of the latent variables were also analyzed. Figures 1 and 2 show the results of those relationships expressed in the first six sets of hypotheses of the UK and Vietnam subsamples, respectively, while table 5 indicates the fitness indices of these two samples.

Insert Figures 2 and 3, and Table 5 about here

H1a states that investment in training and development is positively associated with team learning and that the relationship is stronger among the UK employees than is the case among their Vietnamese counterparts. The results show a significant relationship only in the Vietnam sample $(\beta=.437 * * *)$. Thus, $\mathrm{H} 1 \mathrm{a}$ is only partly supported.

$\mathrm{H} 1 \mathrm{~b}$ investigates the relationship between investment in training and development and knowledge sharing, and that the relationship is stronger among the UK employees than compared with Vietnamese counterparts. The results show insignificant relationships in both subsamples. Thus, $\mathrm{H} 1 \mathrm{~b}$ is rejected.

$\mathrm{H} 2 \mathrm{a}$ investigates the relationship between developmental leadership and team learning and that the relationship is stronger among the UK employees than is the case among their Vietnamese counterparts. The results show insignificant relationships in both subsamples. Thus, H2a is rejected. 
$\mathrm{H} 2 \mathrm{~b}$ states that developmental leadership is positively associated with knowledge sharing and that the relationship is stronger among the UK employees than is the case among their Vietnamese counterparts. The results show a negative relationship among the UK employees $\left(\beta=-.240^{*}\right)$ while it is insignificant among the Vietnamese counterparts. Thus, $\mathrm{H} 2 \mathrm{~b}$ is rejected.

H3a states that team commitment is positively associated with team learning and that the relationship is similar in both contexts. The relationship is seen positive among the UK employees $\left(\beta=.303^{* *}\right)$ but insignificant among the Vietnamese counterparts. Thus, H3a is partly supported.

$\mathrm{H} 3 \mathrm{~b}$ investigates the positive relationship between team commitment and knowledge sharing, and the relationship is similar in both contexts. The results show a positive relationship among the Vietnamese employees $\left(\beta=.424^{* *}\right)$, but an insignificant one among the UK counterparts. Thus, H3b is partly supported.

$\mathrm{H} 4 \mathrm{a}$ states that motivation is positively associated with team learning, and that the relationship is stronger among Vietnam employees than is the case among their UK counterparts. The results show significant result among the UK employees $(\beta=$ $\left..323^{*}\right)$. Thus, $\mathrm{H} 4 \mathrm{a}$ is partly supported.

H4b states that motivation is positively associated with knowledge sharing, and that the relationship is stronger among Vietnam employees than is the case among their UK counterparts. The results indicate significant relationship in both subsamples, but higher among the UK employees $(B=.619 * * *$ for the UK subsample and $B=.424 * *$ for the Vietnam subsample). Thus, $\mathrm{H} 4 \mathrm{~b}$ is mainly supported.

H5a investigates the relationships between team learning and self-efficacy. The results show no significant relationship in both subsamples. Thus, H5a is rejected. H5b states a positive relationship between knowledge sharing and self-efficacy. 
The results are similar in both subsamples $\left(\beta=.508^{* * *}\right.$ for the UK subsample, and $\beta$ $=.637^{* * *}$ for the Vietnam subsample). Thus, H5b is supported.

H6a states that self-efficacy is positively associated with research performance, and that the relationship is stronger among the UK employees than is the case among their Vietnamese counterparts. The results show significant relationship among the UK employees only $\left(\beta=.670^{* * *}\right)$. Thus, H6a is partly supported.

H6b states that self-efficacy is positively associated with individual learning, and that the relationship is stronger among the UK employees than is the case among their Vietnamese counterparts. The results show a significant relationship in both subsamples. ( $\beta=.453^{* * *}$ for the UK's, and $\beta=.430^{* * *}$ for Vietnam's). Thus, H6b is supported.

Based on the results of these above hypotheses and strictly following Baron and Kenny's (1986) requirements, we conducted an indirect model test to examine the mediating effects proposed in $\mathrm{H7a}, \mathrm{H} 7 \mathrm{~b}, \mathrm{H} 7 \mathrm{c}$, and $\mathrm{H} 7 \mathrm{~d}$. Tables 6 and 7 show the results of mediating effects in $\mathrm{H} 7 \mathrm{~s}$ and the fit index of those mediating effect models.

Insert Tables 6 and 7 about here

The results show different mediating effects in the two subsamples. The Vietnam subsample shows that knowledge sharing mediates the relationships between motivation and self-efficacy $\left(\beta=.383^{* * *}\right)$, and team commitment and self-efficacy $(\beta$ $\left.=.224^{* *}\right)$, and self-efficacy mediates the relationship between knowledge sharing and individual learning $\left(\beta=.518^{* * *}\right)$. The UK subsample shows that knowledge sharing mediates the relationships between motivation and self-efficacy $\left(\beta=.316^{* *}\right)$, selfefficacy mediates the relationships between knowledge sharing and individual 
learning $(\beta=.329 * * *)$, and between knowledge sharing and research performance $(\beta$ $\left.=.378^{* *}\right)$. Thus, $\mathrm{H} 7 \mathrm{~s}$ are partially supported.

\section{Discussion}

In this article, we studied team learning within the context of higher education in Vietnam and the UK, and used 'attitude towards team learning' as its proxy construct. We identified and measured a set of antecedents that were expected to influence team learning as well as the consequences of team learning (via the mediation of selfefficacy) - in particular, individual learning and research performance of academics. Providing insights of team learning within this sector, this study offers a more extensive understanding of team learning compared to the extant team learning literature. Our analysis reveals a number of important insights and contributions, which we discuss in turn.

The results generally support our suggested model, although not all the anticipated associations were verified, and the results are slightly different in the two contexts. Moderation of the culture (as represented by the nationality of the two institutions) was supported for a number of the associations, indicating that different factors influence individual learning and performance, and that the role knowledge sharing plays is important in generating self-efficacy. Self-efficacy, in line with existing knowledge, mediated the relationships between the intermediate variable knowledge sharing - and the outcomes of individual learning.

Some results were similar in both cultures; for example, team commitment and motivation were positively associated with team learning and knowledge sharing supporting the general relevance of knowledge in institutions operating in a knowledge-intensive environment (Akbar, 2003; Nonaka \& Takeuchi, 1995). 
Learning, including team learning, requires a high motivation level (Hogan \& Warrenfeltz, 2003; Leung, Chen, \& Chen, 2014).

Development and learning, and leadership were less influential, possibly due to the academic nature of the measures, where individual academics tend to develop and lead themselves (Baruch \& Hall, 2004). 'Development and training' is associated with team learning only in the context of Vietnam. As we have argued in our hypothesis development, this finding shows a greater effect of development and training on team learning in the context of a developing country. Developmental leadership is associated with team learning only in the context of the UK. This finding reflects the reality of the under-developed area of leadership in the context of a developing country like Vietnam.

The study shows that knowledge sharing is associated with individual learning via full or partial mediation of self-efficacy. These relationships hold true in both cultures, manifesting the robustness of the association, and confirm the extant literature (Bartol \& Srivastava, 2002; Ipe, 2003).

Surprisingly, team learning is not associated with either self-efficacy or research performance. This is possibly due to the pressures of internal competition in publishing among academics around the world (Xu, Yalcinkaya, \& Seggie, 2008). The relationships remain the same when looking at each culture separately. This important finding raises an issue in the higher education sector that they do not practice what they teach, i.e., building teamwork/team learning among their students

Finally, control variables can play a critical role in the framework. For example, high qualifications such as $\mathrm{PhD}$ degrees have highly significant impacts on research performance in both Vietnam and UK contexts. 
Overall, our results contribute to organizational learning theory by indicating factors that lead to improved team learning, and the relevance of team learning on self-efficacy and academic performance.

\section{Practical implications}

Apart from the theoretical implications, we offer a number of practical implications that merit the attention of human resource managers in general, and in higher education in particular. First, team learning needs more attention from managers, particularly in the case of the higher education sector. Although the literature has shown the significance of team learning on organizational performance and organizational competitive advantage in other sectors (Ely, Padavic, \& Thomas, 2012; Hirst, Van Knippenberg, \& Zhou, 2009; Li, Chun, Ashkanasy, \& Ahlstrom, 2012), higher education arguably fails to employ team learning in improving research performance. Thus, we suggest that higher education should change the mechanism of team learning in order to encourage and motivate more learning within internal teams to the same extent as learning within external teams is encouraged.

Second, knowledge sharing demonstrates its critical role in higher education as it can help improve self-efficacy as well as individual learning. Managers should also be aware of the fact that the components of knowledge sharing can vary from one context to the other. Thus, they should learn carefully about characteristics of their teams in order to ensure knowledge sharing.

\section{Limitations and future research}

The data are drawn from two universities, one in Vietnam and one in the UK, both large and well-established institutions. Although this allowed for an in-depth analysis, 
the uniqueness of our sample may limit the generalizability of the findings beyond that context. Using a cross-sectional design might be associated with common method bias, although we tested for the Harman Single Factor. To validate and strengthen this framework, future research should also clarify and examine the roles of internal and external teams on academics' collective team learning. In addition, this model would benefit from being tested outside the higher education sector to conform more widely to its applicability. Furthermore, we used individual respondents to draw team-level inferences. Lastly, the differences between the two contexts found through this study indicate that team learning in different contexts is a hidden charm that needs exploring further.

\section{Conclusion}

This paper contributes to learning theory and literature at both the team and organizational levels, beyond individual level learning (Klein \& Kozlowski, 2000). It also offers ideas about the specific role of knowledge sharing, not just team learning, in generating individual performance within both cultures, individualistic and collectivist. We have identified the highly relevant mediating role of knowledge sharing on the consequences of self-efficacy. These findings have emerged from examining the higher education sector in the two different contexts of the UK and Vietnam. Hence, the suggested model offers a new perspective of team learning theory as well as related practical implications, from perspectives of not just typical Western, but also Asia-Pacific, management. 


\section{References}

Ahlstrom, D. 2012. On the types of papers the Asia Pacific Journal of Management generally publishes. Asia Pacific Journal of Management, 29: 1-7.

Akbar, H. 2003. Knowledge levels and their transformation: towards the integration of knowledge creation and individual learning. Journal of Management Studies, 40: 1997-2021.

Akgun, A. E., Lynn, G. S., Keskin, H., \& Dogan, D. 2013. Team learning in IT implementation projects: Antecedents and consequences. International Journal of Inofrmation Management, 34(1): 37-47.

Alvesson, M., \& Sandberg, J. 2013. Has management studies lost its way? Ideas for more imaginative and innovative research. Journal of Management Studies, 50: $128-152$.

Bacon, N., \& Blyton, P. 2003. The impact of teamwork on skills: Employee perceptions of who gains and who loses. Human Resource Management Journal, 13(2): 13-29.

Bandura, A. 1986. Social Foundation of Thought and Action: A Social Cognitive Theory. Englewood Cliffs, NJ: Prentice-Hall

Bandura, A. 1977. Self-efficacy: The Exercise of Control. New York: Freeman.

Baron, K. E., \& Kenny, D. A. 1986. The moderator-mediator variable distinction in social psychological research: conceptual, strategic, and statistical considerations. Journal of Personality and Social Psychology, 51: 11731182.

Bartol, K. M., \& Srivastava, A. 2002. Encouraging knowledge sharing: The role of organizational reward systems. Journal of Leadership \& Organizational Studies, 9(1): 64-76. 
Baruch, Y. 2013. Careers in Academe: The Academic Labour Market as an EcoSystem. Career Development International, 18: 196-210.

Baruch, Y., \& Hall, D. T. 2004. The academic career: A model for future careers in other sectors? Journal of Vocational Behavior, 64: 241-262.

Bell, J., \& Harrison, B. T. 1998. Leading People: Learning from People. Buckingham: Open University Press.

Bennett, R., \& Barkensjo, A. 2005. Internal marketing, negative experiences, and volunteers' commitment to providing high-quality services in a UK helping and caring charitable organization. International Journal of Voluntary and Nonprofit Organizations, 16: 251-274.

Bishop, J., Scott, K. D., \& Burroughs, S. M. 2000. Support, commitment, and employee outcomes in a team environment. Journal of Management, 26: 1113-1132.

Bock, G.-W., Zmud, R. W., Kim, Y.-G., \& Lee, J.-N. 2005. Behavioral intention formation in knowledge sharing: examining the roles of extrinsic motivators, social-psychological forces, and organizational climate. MIS Quarterly, 29: 87-111.

Boland, R. J. \& Tenkasi, R. V. 1995. Perspective making and perspective taking in communities of knowing. Organization Science, 6: 350-372

Bowen, D. D. 1998. Team frames: the multiple realities of the team. Journal of Management Education, 22: 95-103.

Bresman, H., \& Zellmer-Bruhn, M. 2013. The structural context of team learning: Effects of organizational and team structure on internal and external learning. Organization Science, 24: 1120-1139. 
Brislin, R. W. (Ed.). 1976. Translation Applications and Research. New York: Gouldner Press.

Bui, H. T. M., \& Baruch, Y. 2012. Learning organizations in higher education: An empirical evaluation within an international context. Management Learning, 43: $515-544$

Byrne, B. M. (2012). Structural Equation Modeling with Mplus: Basic Concepts, Applications and Programming. New York: Routledge

Chen, G., Donahue, L. M., \& Klimoski, R. J. 2004. Training undergraduates to work in organizational teams. Academy of Management, Learning and Education, 3: $27-40$.

Collings, D. G., Morley, M. J., \& Gunnigle, P. 2008. Composing the top management team in the international subsidiary: Qualitative evidence on international staffing in US MNCs in the Republic of Ireland. Journal of World Business, 43: $197-212$

Dalin, P. 1998. School Development Theories and Strategies. London: Cassell.

De Geus, A. P. 1988. Planning as learning. Harvard Business Review, 66(2): 70-74.

Edmondson, A. C. 1999. Psychological safety and learning behavior in work teams. Administrative Science Quarterly, 44: 350-383.

Edmondson, A. C. 2002. The local and variegated nature of learning in organizations: A group-level perspective. Organization Science, 13: 128-146.

Edmondson, A. C., Bohmer, R., \& Pisano, G. 2004. Speeding up team learning, Harvard Business Review in Teams That Succeed: 77-98. Boston: Harvard Business School Publishing Corporation. 
Edmondson, A. C., Bohmer, R. M., \& Pisano, G. P. 2001. Disrupted routines: Team learning and new technology implementation in hospitals. Administrative Science Quarterly, 46: 685-716.

Ely, R. J., Padavic, I., \& Thomas, D. A. 2012. Racial diversity, racial asymmetries, and team learning environment: Effects on performance. Organization Studies, 33: 341-362.

Faraj, S. \& Sproull, L. 2000. Coordinating expertise on software development team. Management Science, 46: 1554-1568.

Gagne, M. 2009. A model of knowledge sharing motivation. Human Rresource Management, 48: 571-589.

Gibson, C. \& Vermeulen, F. 2003. A health divide: Subgroup as a stimulus for team learning behavior. Adminstrative Science Quarterly, 48: 202-239.

Graen, G. B., Hui, C., \& Taylor, E. A. 2006. Experience-based learning about LMX leadership and fairness in project teams: A dyadic directional approach. Academy of Management, Learning and Education, 5: 448-460.

Hakima, N., Knippenberg, D. V., \& Giessner, S. 2010. Leader empowering behaviour: The leader's perspective. British Journal of Management, 21: 701-716.

Han, T. W., \& Williams, K. J. 2008. Multilevel investigation of adaptive performance: individual- and team-level relationships. Group \& Organization Management, 33: 657-584.

He, H., Baruch, Y., \& Lin, C. P. 2014. Modeling team knowledge sharing and team flexibility: The role of within-team competition. Human Relations, 57, 947978. 
Hendriks, P. 1999. Why share knowledge? The influence of ICT on the motivation for knowledge sharing. Knowledge and Process Management, 6: 91-100.

Hirst, G., Van Knippenberg, V., \& Zhou, Z. 2009. A cross-level perspective on employee creativity: Goal orientation, team learning behavior, and individual creativity. Academy of Management Journal, 52: 280-293.

Hofstede, G. 1984. Cultural dimensions in management and planning. Asian Pacific Journal of Management, 1(2): 81-99.

Hofstede, G. 2001. Culture's Consequences. Thousand Oaks, CA: Sage Publications.

Hogan, R., \& Warrenfeltz. 2003. Educating the modern manager. Academy of Management, Learning and Education, 2: 74-84.

House, R. J., Hanges, P. J., Javidan, M., Dorfman, P. W., \& Gupta, V. (Eds.). 2004. Culture, Leadership, and Organizations: The GLOBE Study of 62 Societies. London: Sage.

Hülsheger, U. R., Anderson, N., \& Salgado, J. F. 2009. Team-level predictors of innovation at work: a comprehensive meta-analysis spanning three decades of research. Journal of Applied psychology, 94(5): 1128-1145.

Ipe, M. 2003. Knowledge sharing in organizations: A conceptual framework. Human Resource Development Review, 2(4): 337-359.

Jassawalla, A., Sashittal, H., \& Malshe, A. 2009. Students' perceptions of social loafing: Its antecedents and consequences in undergraduate business classroom teams. Academy of Management, Learning and Education, 8: $42-$ 54.

Kinchin, I. M., Lygo-Baker, S., \& Hay, D. B. 2008. Universities as centres of nonlearning. Studies in Higher Education, 33: 89-103. 
Klein, K. J., \& Kozlowski, S. W. J. 2000. Multilevel Theory, Research, and Methods in Organizations: Foundations, Extensions, and New Directions. New York: Wiley.

Kline, R. B. 2006. Principles and Practice of Structural Equation Modeling (2nd ed.). New York: Guilford Press.

Kostopoulos, K. C., \& Bozionelos, N. 2011. Team exploratory and exploitative learning: Psychological safety, task conflict, and team performance Group \& Organization Management, 36: 385-415.

Kostopoulos, K. C., Spanos, Y. E., \& Prastacos, G. P. 2013. Structure and function of team learning emergence: A multilevel empirical validation. Journal of Management, 39: 1430-1461.

Lee, P., Gillsepie, N., Mann, L. \& Wearing, A. 2010. Leadership and trust: Their effect on knowledge sharing and team performance. Management Learning, 28: 473-491

Leung, K., Chen, T., \& Chen, G. 2014. Learning goal orientation and creative performance: The differential mediating roles of challenge and enjoyment intrinsic motivations. Asia Pacific Journal of Management, 31: 811-834.

Li, Y., Chen, H., Loiu, Y., \& Peng, M. W. 2012. Managerial ties, organizational learning, and opportunity capture: A social capital perspective. Asia Pacific Journal of Management. 31: 271-291.

Li, Y., Chun, H., Ashkanasy, N., \& Ahlstrom, D. 2012. A multi-level study of emergent group leadership: Effects of emotional stability and group conflict. Asia Pacific Journal of Management, 29: 351-366.

Malgady, R. G. 2007. How skewed are psychological data? A standardized index of effect size. The Journal of General Psychology, 134(3): 355-359. 
Marsick, V. J., \& Watkins, K. E. 2003. Demonstrating the value of an organization's learning culture: the dimensions of the learning organization questionnaire. Developing Human Resources 5: 132-151.

Meyer, J. P., \& Allen, N. J. 1991. A three components conceptualization of organizational commitment. Human Resource Management Review, 1: 6189.

Milia, L. D., \& Birdi, K. 2010. The relationship between multiple levels of learning practices and objective and subjective organizational financial performance. Journal of Organizational Behavior, 31: 481-498.

Molnar, E., \& Mulvihill, P. R. 2003. Sustainability-focused organizational learning: recent experiences and new challenges. Journal of Environmental Planning and Management, 46: 167-176.

Muthén, L. K., \& Muthén, B. O. (2012). Mplus. The Comprehensive Modelling Program for Applied Researchers: User's guide, 5.

Nguyen, T. N., Truong, Q., \& Dirk, B. 2011. Training and firm performance in economies in transition: A comparison between Vietnam and China. Asia Pacific Business Review, 17: 103-119.

Nissala, S.-P. 2005. Individual and collective reflection: how to meet the needs of development in teaching. European Journal of Teacher Education, 28: 209219.

Nonaka, I., \& Takeuchi, H. 1995. The Knowledge Creating Company. Oxford: Oxford University Press.

Ooi, K.-B., Cheah, W.-C., Lin, B., \& Teh, P.-L. 2012. TQM practices and knowledge sharing: An empirical study of Malaysia's manufacturing organizations. Asia Pacific Journal of Management, 29: 59-78. 
Park, S., Henkin, A. B., \& Egley, R. 2005. Teacher team commitment, teamwork and trust: exploring associations. Journal of Educational Administration, 43: 462-479.

Pichault, F. 2007. HRM-based reforms in public organization: Problems and perspectives. Human Resource Management Journal, 17:265-282.

Pintrich, P. R. 2003. A motivational science perspective on the role of student motivation in learning and teaching contexts. Journal of Educational Psychology, 95: 667-686.

Podsakoff, P. M., MacKenzie, S. B., Podsakoff, N. P. 2012. Sources of method bias in social science research and recommendations on how to control it. Annual Review of Psychology, 63 (2012), pp. 539-569

Podsakoff, P. M., Mackenzie, S. B., Lee, J.-Y., \& Podsakoff, N. P. 2003. Common method biases in behavioral reseach: a critical review of the literature and recommendation remedies. Journal of Applied Psychology, 88(5): 879-903.

Porter, L. W., Steers, R. M., Mowday, R. T., \& Boulian, P. V. 1974. Organizational commitment, job satisfaction and turnover among psychiatric technicians. Journal of Applied Psychology, 59: 603-609.

Prichard, J., \& Ashleigh, M. 2012. An integrative model of trust's role in transactive memory development. Group \& Organization Management. 38: 696-726.

Prichard, J. S., Stratford, R. J., \& Bizo, L. A. 2006. Team-skills training enhances collaborative learning. Learning and Instruction, 16: 256-265.

Reed, H. A. 2001. Ukrop's as a learning organization: Senge's five disciplines realized in a medium-sized company. University of Virginia, Charlottesville. 
Quian, C., Cao, Q., \& Takeuchi, R. 2013. Top management team functional diversity and organizational innovation in China: The moderating effects of environment. Strategic Management Journal, 34: 110-120.

Raes, A. M., Bruch, H., \& De Jong, S. B. 2013. How top management team behavioural integration can impact employee work outcomes: Theory development and first empirical tests Human Relations, 66: 167-192.

Sackney, L., \& Walker, K. 2006. Canadian perspectives on beginning principals: their role in building capacity for learning communities Journal of Educational Administration, 44: 341-358.

Schunk, D. H. 1991. Self-efficacy and academic motivation. Educational Psychologist, 26: 207-231.

Senge, P. 1990. The Fifth Discipline the Art \& Practice of the Learning Organization. NSW: Random House Australia.

Senge, P. M. 2006. The Fifth Discipline: The Art and Practice of the Learning Organization ( $2^{\text {nd }}$ ed.). London: Random House.

Seo, M. 2003. Overcoming emotional barriers, political obstacles, and control imperatives in the action-science approach to individual and organizational learning. Academy of Management, Learning and Education, 2: 7-21.

Siebold, G. L. 1994. The relation between soldier motivation, leadership, and small unit performance. In H. F. O'Neil, \& J. M. Drillings (Eds.), Motivation Theory and Research: 171-190. Hove, UK: Lawrence Erlbaum Associates.

Smith, E. D., \& Pham, C. 1996. Doing business in Vietnam: a cultural guide. Business Horizon, 39(3): 47-52. 
Sperber, A. D., Devellis, R. R., \& Boehlecke, B. 1994. Cross-cultural translation: methodology and validation. Journal of Cross-Cultural Psychology, 25: 501524.

Srivastava, A., Bartol, K. M., \& Locke, E. A. 2006. Empowering leadership in management teams: Effects on knowledge sharing, efficacy, and performance. Academy of Management, 49: 1239-1251.

Strauss, K., Griffin, M. A., \& Rafferty, A. E. 2009. Proactivity directed toward the team and organization: The role of leadership, commitment and role-breadth self-efficacy. British Journal of Management, 20: 279-291.

Tabachnick, B. G., \& Fidell, L. S. 2001. Using Multivariate Statistics (4 ${ }^{\text {th }}$ ed.). Boston: Allyn \& Bacon.

Tashchian, A., Forrester, W. R., \& Kalamas, M. 2014. The effects of extroversion on conflict resolution in student teams: A cross-cultural comparison. Journal of International Education Research, 10: 29-35.

Tsai, F. S., Baugh, G. S., Fang, S. C., \& Lin, J. L. 2014. Contingent contingency: Knowledge heterogeneity and new product development performance revisited. Asia Pacific Journal of Management, 31: 149-169.

Thêm, T. N. 1999. Fundamental Vietnamese Culture. Ho Chi Minh: Education Publishing.

Tierney, P., \& Farmer, S. 2002. Creative self-efficacy: its potential antecedents and relationship to creative performance. Academy of Management Journal, 45: $1137-1148$

Tjosvold, D., Yu, Z., \& Hui, C. 2004. Team learning from mistakes: The contribution of cooperative goals and problem-solving. Journal of Management Studies, 41: 1223-1245. 
Vượng, T. Q. 2001. Vietnamese Culture: Exploring and Understanding. Hanoi: Literature Publishing.

Vuong, T. Q., Thanh, T. N., Ben, N. C., Dzung, L. M., \& Anh, T. T. 1999. Fundamental Vietnamese Culture. Hanoi: Education Publishing.

Wang, Z., Tjosvold, D., Chen, Y. F. N., \& Luo, Z. (2014). Cooperative goals and team performance: Examining the effects of advice network. Asia Pacific Journal of Management, 31: 835-852.

Wilson, J., Goodman, P. S. \& Cronni, M. A. 2007. Group learning. Academy of Management Review, 32: 1041-1059.

West, M. A. 2004. Effective Teamwork: Practical Lessons from Organizational Research $\left(2^{\text {nd }}\right.$ ed.). Oxford: BPS Blackwell.

Woodfield, S., \& Kennie, T. 2008. 'Teamwork' or 'working as a team'? The theory and practice of top team working in UK Higher Education. Higher Education Quarterly, 62(4): 397-415.

Xu, S., Yalcinkaya, G., \& Seggie, S. H. 2008. Prolific authors and institutions in leading international business journals. Asia Pacific Journal of Management, 25: 189-207.

Yang, H., Sun, S. L., Lin, Z. J., \& Peng, M. W. 2011. Behind M\&As in China and the United States: Networks, learning, and institutions. Asia Pacific Journal of Management, 28: 239-255. 
Figure 1: Conceptual model

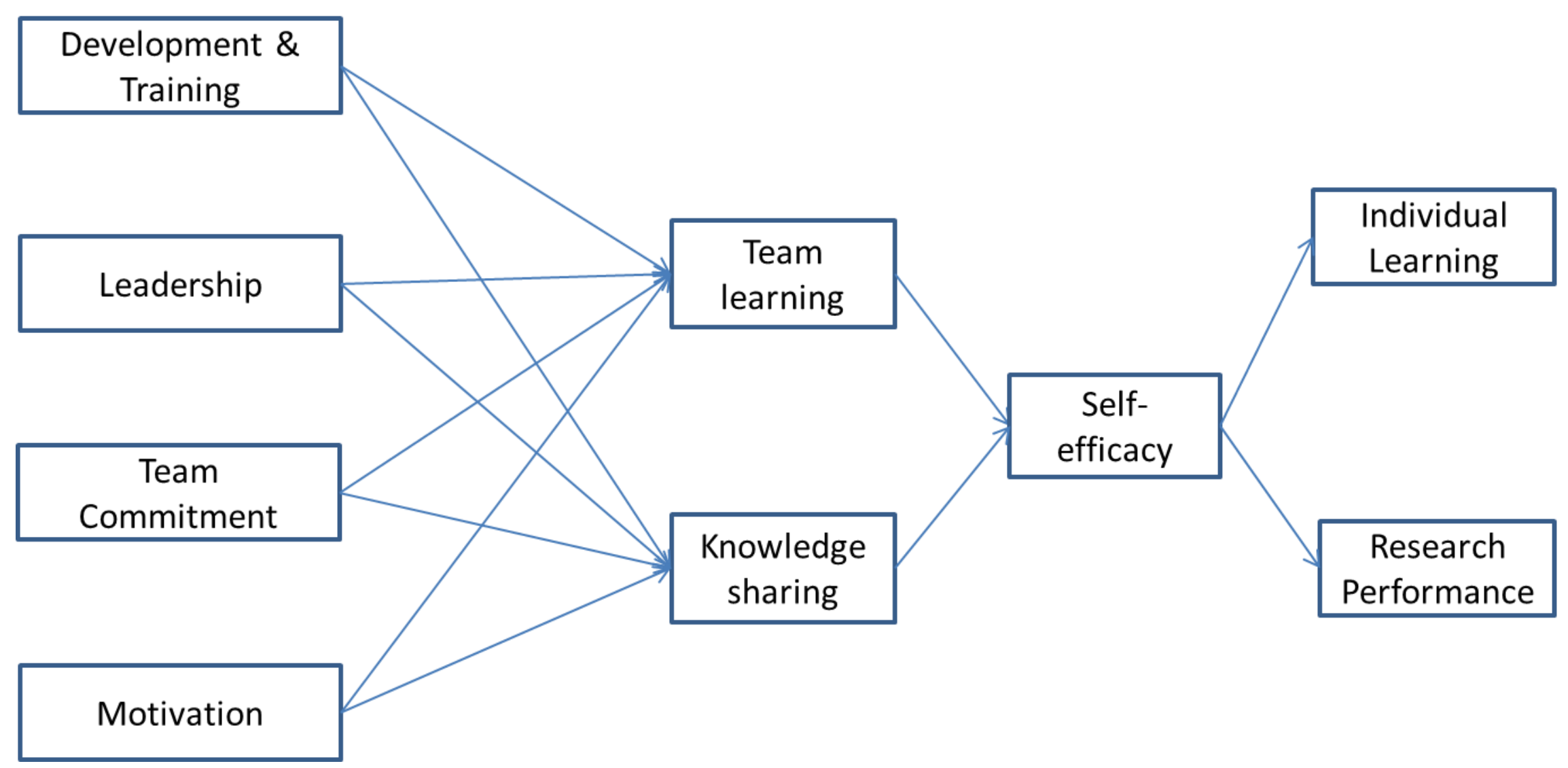


Table 1. Sample table

\begin{tabular}{|l|c|c|c|c|c|c|c|c|c|c|c|c|}
\hline & Total & $\begin{array}{c}\text { Response } \\
\text { rate }\end{array}$ & PhD & MSc & $\begin{array}{c}\text { PG } \\
\text { Cert }\end{array}$ & Degree & Lecturer & $\begin{array}{c}\text { Senior } \\
\text { lecturer }\end{array}$ & Reader & Professor & Researcher & $\begin{array}{c}\text { Academic } \\
\text { manager }\end{array}$ \\
\hline VN & 204 & $45.3 \%$ & 113 & 60 & 3 & 29 & 97 & 39 & 47 & 5 & 18 & 28 \\
\hline UK & 197 & $44.7 \%$ & 164 & 11 & 3 & 7 & 46 & 33 & 16 & 35 & 50 & 7 \\
\hline
\end{tabular}


Table 2. Correlation table (aggregate sample $\mathrm{N}=383$ )

\begin{tabular}{|l|r|r|r|r|r|l|l|l|l|l|l|}
\hline & Mean & Std deviation & PA3 & DT & L & TC & SE & KS & IL & M & TL \\
\hline Research performance & 3.78 & 1.943 & & & & & & & & \\
\hline Development \& training & 4.69 & 1.427 & -.097 & $(.86)$ & & & & & & & \\
\hline Developmental leadership & 4.87 & 1.303 & -.042 & $.465^{* *}$ & $(.90)$ & & & & & & \\
\hline Team commitment & 5.67 & 1.113 & -.040 & $.433^{* *}$ & $.377^{* *}$ & $(.84)$ & & & & & \\
\hline Self-efficacy & 5.61 & .913 & $.209^{* *}$ & $.149^{* *}$ & $.161^{* *}$ & $.323^{* *}$ & $(.76)$ & & & & \\
\hline Knowledge sharing & 5.46 & 1.180 & -.025 & $.359^{* *}$ & $.224^{* *}$ & $.490^{* *}$ & $.448^{* *}$ & $(.94)$ & & & \\
\hline Individual learning & 6.06 & .935 & -.019 & $.284^{* *}$ & $.150^{* *}$ & $.432^{* * *}$ & $.398^{* *}$ & $.544^{* *}$ & $(.90)$ & & \\
\hline Motivation & 5.96 & .895 & $.112^{*}$ & $.308^{* *}$ & $.277^{* *}$ & $.447^{* *}$ & $.438^{* *}$ & $.446^{* *}$ & $.550^{* *}$ & $(.73)$ & \\
\hline Attitude towards team learning & 4.68 & 1.113 & $.105^{*}$ & $.362^{* *}$ & $.422^{* *}$ & $.416^{* *}$ & $.362^{* *}$ & $.294^{* *}$ & $.234^{* *}$ & $.407^{* *}$ & $(.86)$ \\
\hline
\end{tabular}

**. Correlation is significant at the 0.01 level (2-tailed).

*. Correlation is significant at the 0.05 level (2-tailed).

(): Cronbach Alpha 
Table 3. Correlations (VN sample $\mathrm{N}=204$ )

\begin{tabular}{|l|r|r|r|r|l|l|l|l|l|l|l|}
\hline & Mean & Std deviation & PA3 & DT & L & TC & SE & KS & IL & M & TL \\
\hline Research performance & 3.42 & 1.957 & & & & & & & & \\
\hline Development \& training & 5.32 & 1.285 & .014 & $(.79)$ & & & & & & & \\
\hline Developmental leadership & 4.99 & 1.401 & -.057 & $.490^{* *}$ & $(.92)$ & & & & & & \\
\hline Team commitment & 5.94 & 1.094 & -.009 & $.364^{* *}$ & $.332^{* *}$ & $(.91)$ & & & & & \\
\hline Self-efficacy & 5.59 & .993 & $.175^{*}$ & $.249^{* *}$ & $.253^{* *}$ & $.449^{* *}$ & $(.80)$ & & & & \\
\hline Knowledge sharing & 5.89 & 1.125 & .053 & $.324^{* *}$ & $.308^{* *}$ & $.605^{* *}$ & $.567^{* *}$ & $(.94)$ & & & \\
\hline Individual learning & 6.29 & .944 & .054 & $.240^{* *}$ & .112 & $.543^{* *}$ & $.402^{* *}$ & $.572^{* *}$ & $(.90)$ & & \\
\hline Motivation & 5.88 & .947 & $.141^{*}$ & $.387^{* *}$ & $.216^{* *}$ & $.494^{* *}$ & $.475^{* *}$ & $.585^{* *}$ & $.600^{* *}$ & $(.82)$ & \\
\hline Attitude towards team learning & 4.70 & 1.126 & .132 & $.539^{* *}$ & $.464^{* *}$ & $.372^{* *}$ & $.469^{* *}$ & $.379^{* *}$ & $.204^{* *}$ & $.443^{* *}$ & $(.82)$ \\
\hline
\end{tabular}

**: significant at the 0.01 level (2-tailed).

$*$ : significant at the 0.05 level (2-tailed). 
Table 4. Correlations (UK sample $\mathrm{N}=179$ )

\begin{tabular}{|l|r|r|r|r|r|r|r|l|l|l|l|}
\hline & Mean & Std deviation & PA3 & DT & L & TC & SE & KS & IL & M & TL \\
\hline Research performance & 4.18 & 1.85 & & & & & & & & \\
\hline Development \& training & 3.97 & 1.23 & -.029 & $(.71)$ & & & & & & & \\
\hline Developmental leadership & 4.74 & 1.17 & .023 & $.467^{* *}$ & $(.86)$ & & & & & & \\
\hline Team commitment & 5.36 & 1.05 & .039 & $.362^{* *}$ & $.419^{* *}$ & $(.76)$ & & & & & \\
\hline Self-efficacy & 5.63 & .81 & $.258^{* *}$ & .83 & .018 & $.189^{*}$ & $(.67)$ & & & & \\
\hline Knowledge sharing & 4.97 & 1.05 & .060 & .087 & .055 & $.223^{* *}$ & $.392^{* *}$ & $(.90)$ & & & \\
\hline Individual learning & 5.80 & .86 & .005 & .127 & $.160^{*}$ & $.196^{* *}$ & $.446^{* *}$ & $.399^{* *}$ & $(.82)$ & & $(.82)$ \\
\hline Motivation & 5.72 & .82 & .065 & $.306^{* *}$ & $.413^{* *}$ & $.429^{* *}$ & $.349^{* *}$ & $.316^{* *}$ & $.485^{* *}$ & $(.65)$ & \\
\hline Attitude towards team learning & 4.41 & 1.00 & .087 & $.328^{* *}$ & $.369^{* *}$ & $.518^{* *}$ & $.266^{* *}$ & $.343^{* *}$ & $.362^{* *}$ & $.489^{* *}$ & $(.68)$ \\
\hline
\end{tabular}

**: significant at the 0.01 level (2-tailed).

$*$ : significant at the 0.05 level (2-tailed).

Table 5. Fit index of the modified models

\begin{tabular}{|l|c|c|c|c|c|c|}
\hline Fit index & Chi-square & Degree of freedom & RMSEA & CFI & TLI & SMRM \\
\hline Vietnam sample & $556.858^{*}$ & 333 & .057 & .923 & .913 & .073 \\
\hline UK sample & $658.472^{*}$ & 417 & .057 & .881 & .868 \\
\hline
\end{tabular}


Table 6. Results of mediating effects

\begin{tabular}{|c|c|c|c|c|c|}
\hline & Total indirect effect & Estimates & S.E & Est./S.E & Two-tailed $\mathrm{P}$ value \\
\hline \multirow[t]{3}{*}{ Vietnam } & Effects from motivation to self-efficacy & .383 & .094 & 4.092 & .000 \\
\hline & Effects from team commitment to self-efficacy & .224 & .071 & 3.160 & .002 \\
\hline & Effects from knowledge sharing to individual learning & .518 & .121 & 4.275 & .000 \\
\hline \multirow[t]{4}{*}{ UK } & Effects from leadership to self-efficacy & -.097 & .053 & -1.846 & .065 \\
\hline & Effects from motivation to self-efficacy & .316 & .130 & 2.435 & .015 \\
\hline & Effects from knowledge sharing to individual learning & .329 & .082 & 3.921 & .000 \\
\hline & Effects from knowledge sharing to research performance & .378 & .148 & 2.558 & .011 \\
\hline
\end{tabular}

Table 7. Fit index of mediating effect models

\begin{tabular}{|c|c|c|c|c|c|c|}
\hline Fit index & Chi-square & Degree of freedom & RMSEA & CFI & TLI & SMRM \\
\hline Vietnam & 265.559 & 143 & .065 & .936 & .924 & .074 \\
\hline UK & $365.666^{*}$ & 200 & .068 & .887 & .869 & .083 \\
\hline
\end{tabular}


Figure 2: Results of the UK subsample

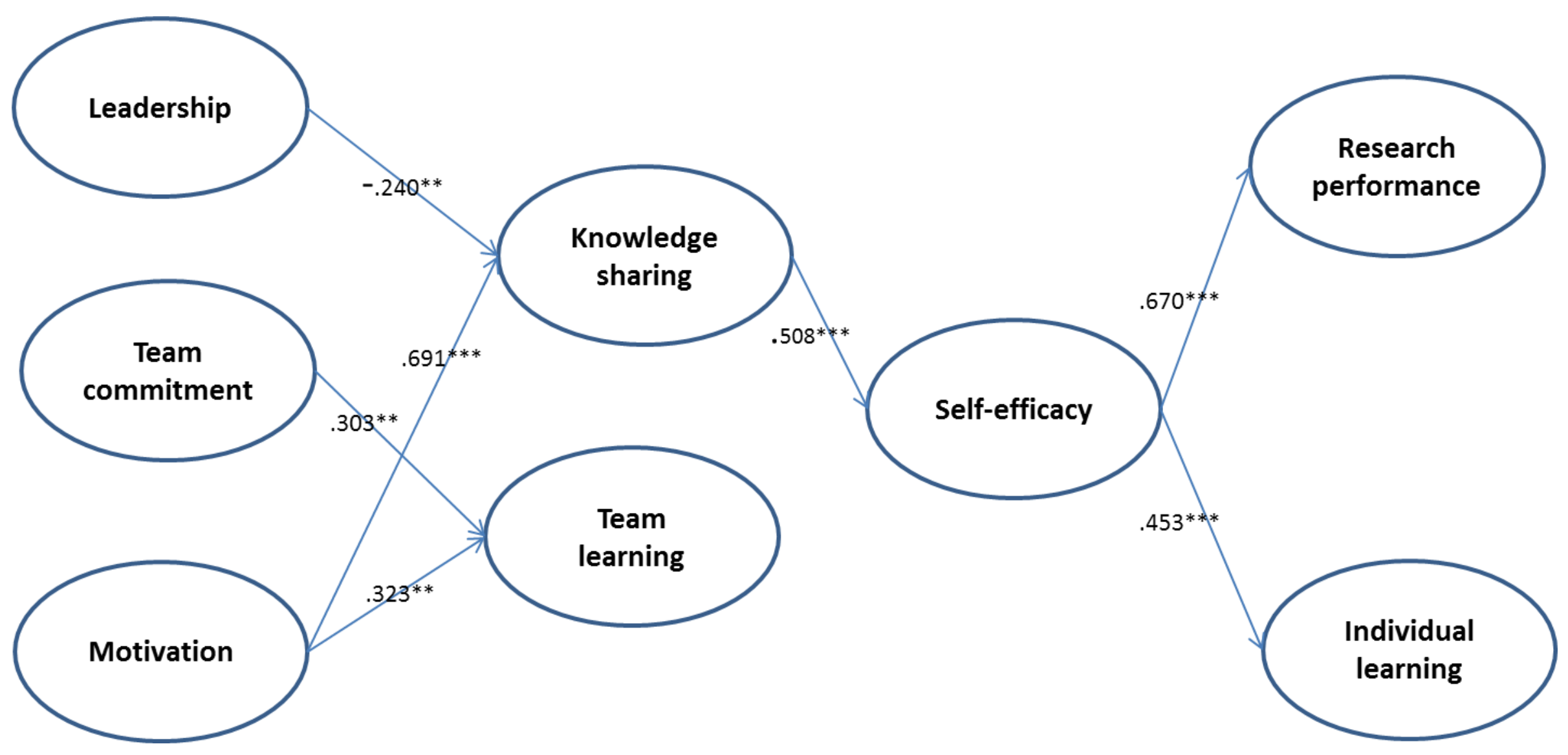

Note: Only significant paths shown

Significance codes: $* * * p<0.001 ; * * p<0.01 ; * \mathrm{p}<0.05$ 
Figure 3: Results of the Vietnam subsample

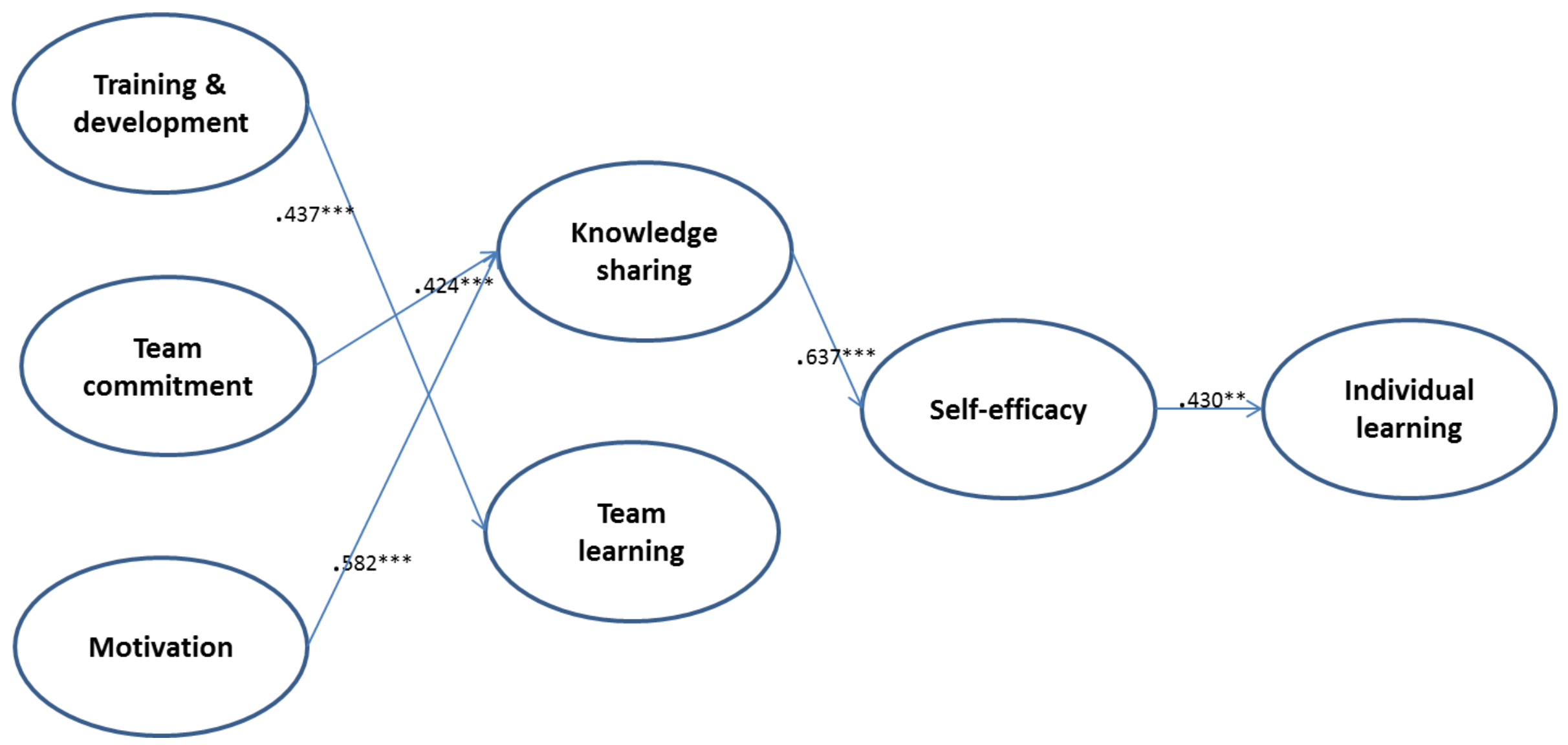

Note: Only significant paths shown

Significance codes: $* * * p<0.001 ; * * p<0.01 ; * p<0.05$ 
Appendix: Measurements

\section{Team learning:}

1. People on my team work well together.

2. I am encouraged to solve problems with my colleagues before discussing them with a manager.

3. This organization encourages team learning and working.

4. We sometimes form informal groups on our own to solve problems within.

5. I solve most problems with help from people from different departments.

\section{Development \& training:}

1. I receive the training I need to perform my current job effectively.

2. I was mentored when I first took up the job here.

3. At this university, staff are encouraged to identify skills they need to adapt to changes.

4. Staff are encouraged to develop team-working skills.

\section{Motivation:}

1. I work hard and try to do as good a job as possible.

2. I look forward to coming to work every day.

3. I am very personally involved in my work.

4. I don't mind taking on extra duties and responsibilities in my work.

\section{Team commitment:}

1. At work, I let myself be guided by the goals of my team.

2. I feel at home among my colleagues at work.

3. I try to invest effort into a good atmosphere in my team.

4. When there is social activity with my team, I usually help to organize it.

\section{Knowledge sharing:}

1. My knowledge sharing would help other members solve problems.

2. My knowledge sharing would improve work processes at work.

3. My knowledge sharing would increase knowledge creation within the organization. 
4. My knowledge sharing would help this university achieve its performance objectives.

\section{Individual learning:}

1. I like being on a steep learning curve at work.

2. I prefer activities that provide me the opportunity to learn something new.

3. My own learning and development at work are essential to me.

4. I like being on a steep learning curve at work.

\section{Self-efficacy:}

1. I am confident about my ability to do my job.

2. I am self-assured about my capacity to perform my work activities.

3. I have mastered the skills necessary for my job.

\section{Developmental leadership:}

1. In our organization leaders/managers continually look for opportunities to learn for their professional development.

2. In our organization leaders/managers generally support requests for training and development opportunities.

3. In our organization leaders/managers empower others to help carry out the organization's vision.

4. In our organization leaders/managers coach those they lead.

5. In our organization leaders/managers ensure that the organization's actions are consistent with its values.

6. In our organization leaders/managers share up-to-date information with employees about the uiversity's directions. 